\title{
KINERJA SISTEM COFDM (CODED ORTHOGONAL FREQUENCY DIVISION MULTIPLEXING) PADA KANAL RADIO MOBILE
}

\author{
Hendra Winata ${ }^{1}$, Heroe Wijanto ${ }^{2}$, Suyatno $^{3}$ \\ Jurusan Teknik Elektro Sekolah Tinggi Teknologi Telkom, Bandung \\ 1endrhax@yahoo.com, ${ }^{2}$ hrw@stttelkom.ac.id
}

\begin{abstract}
Abstrak
Komunikasi data berkecepatan tinggi memerlukan teknik modulasi yang dapat mengatasi terjadinya ISI (Inter-Symbol Interference) dan respons frekuensi kanal yang tidak rata. OFDM (Orthogonal Frequency Division Multiplexing) merupakan teknik transmisi multicarrier dengan periode simbol relatif lebih lebar dibandingkan nilai delay spread kanal. Dengan subcarrier spektral yang lebih sempit dari lebar-pita frekuensi koheren, OFDM diharapkan memiliki ketahanan terhadap gangguan kanal yang tidak rata. FEC (Forward Error Correcting) masih dibutuhkan untuk meminimumkan efek kesalahan akibat dari beberapa subcarrier yang mengalami fading lebih kuat dibandingkan lainnya. FEC dengan teknik pengkodean konvolusional dan interleaver banyak dipakai pada standar OFDM seperti Wireless LAN 802.11a dan Direct Video Broadcasting. Hasil simulasi menunjukkan pengkodean konvolusional [133 171] memberikan nilai coding gain maksimal 6 dB untuk modulasi subcarrier QPSK dan 7 dB untuk 16-QAM. Pada kanal radio mobile dengan frekuensi doppler 0, 9, 56 dan $130 \mathrm{~Hz}$, diperoleh coding gain $7 \mathrm{~dB}$. Penggunaan matriks interleaver $32 \times 18$ (IS-95) bekerja kurang optimal dengan perbaikan daya kurang dari 1dB. Ketika frekuensi doppler $130 \mathrm{~Hz}$, matriks interleaver 100×96 mampu memperbaiki kinerja sistem secara siginifikan, BER di sekitar $10^{-6}$ dicapai pada $S N R=16 \mathrm{~dB}$.
\end{abstract}

Kata kunci: OFDM, interleaver, delay spread, frekuensi doppler, coding gain, IFFT-FFT

\section{Abstract}

High speed data communication needs modulation scheme with capability for handling ISI (Inter-Symbol Interference) and non-flatness of channel frequency response. OFDM (Orthogonal Frequency Division Multiplexing) is a multicarrier transmission technique with symbol period relatively wider then delay spread of the channel, so that the spectral sub-carrier will be more narrow then and flat in coherent bandwidth. FEC (Forward Error Correcting) is still needed to minimize error due to inter-sub-carrier unflatness. FEC with convolutional coding and interleaving widely used in OFDM standards, such as Wireless LAN 802.11a and Direct Video Broadcasting, will be exlopred. Simulation results show convolutional coding [133 171] giving coding gain $6 \mathrm{~dB}$ maximum in QPSK sub-carrier modulation and 7 dB in 16-QAM. In radio mobile channel with $0,9,56$ and $130 \mathrm{~Hz}$ doppler frequency, coding gain will be 7 dB. Interleaver matrix $32 \times 18$ (IS-95) gives less optimal result with less than $1 \mathrm{~dB}$ power improvement. In $130 \mathrm{~Hz}$ doppler frequency channel, interleaver matrix $100 \times 96$ will give significant system performance improvement, BER in around $10^{-6}$ achieved in $\mathrm{SNR}=16 \mathrm{~dB}$.

Keywords: OFDM, interleaver, delay spread, doppler frequency, coding gain, IFFT-FFT

\section{Pendahuluan}

Kebutuhan laju data tinggi untuk layananlayanan komunikasi bergerak telah memacu pengembangan teknik modulasi multicarrier OFDM untuk mengatasi terjadinya ISI (Inter-Symbol Interference) dan karakteristik kanal yang tidak flat. Teknik pengkodean kanal dibutuhkan untuk koreksi error pada beberapa subcarrier yang mengalami fading relatif kuat dibandingkan subcarrier lainnya.

Penelitian ini bertujuan menganalisa kinerja OFDM pada kanal radio mobile dengan fading tidak rata yang diwakili oleh kanal AWGN dan kanal multipath frequency selective fading terdistribusi Rayleigh, untuk kondisi sistem tanpa pengkodean, dengan pengkodean dan dengan sekaligus pengkodean dan interleaver.

\section{Dasar Teori}

OFDM merupakan teknik transmisi multiplexing dari sinyal-sinyal multicarrier yang mengirimkan data secara paralel pada beberapa subcarrier yang saling ortogonal. Spasi antar subcarrier dibuat sedemikian hingga lebih sempit dari lebar-pita frekuensi koheren suatu kanal transmisi. Diharapkan jika kesuluruhan lebar-pita frekuensi yang dialokasikan sangat lebar (karena laju data yang tinggi) semula akan mengalami fading yang tidak rata, setelah dilakukan pemecahan menjadi sejumlah sub-carrier termodulasi, maka masingmasing sub-carrier akan mengalami fading yang rata. Dalam domain waktu, hal ini mensyaratkan pemecahan aliran data secara parallel hendaknya dibuat dengan periode simbol yang lebih pendek dari 


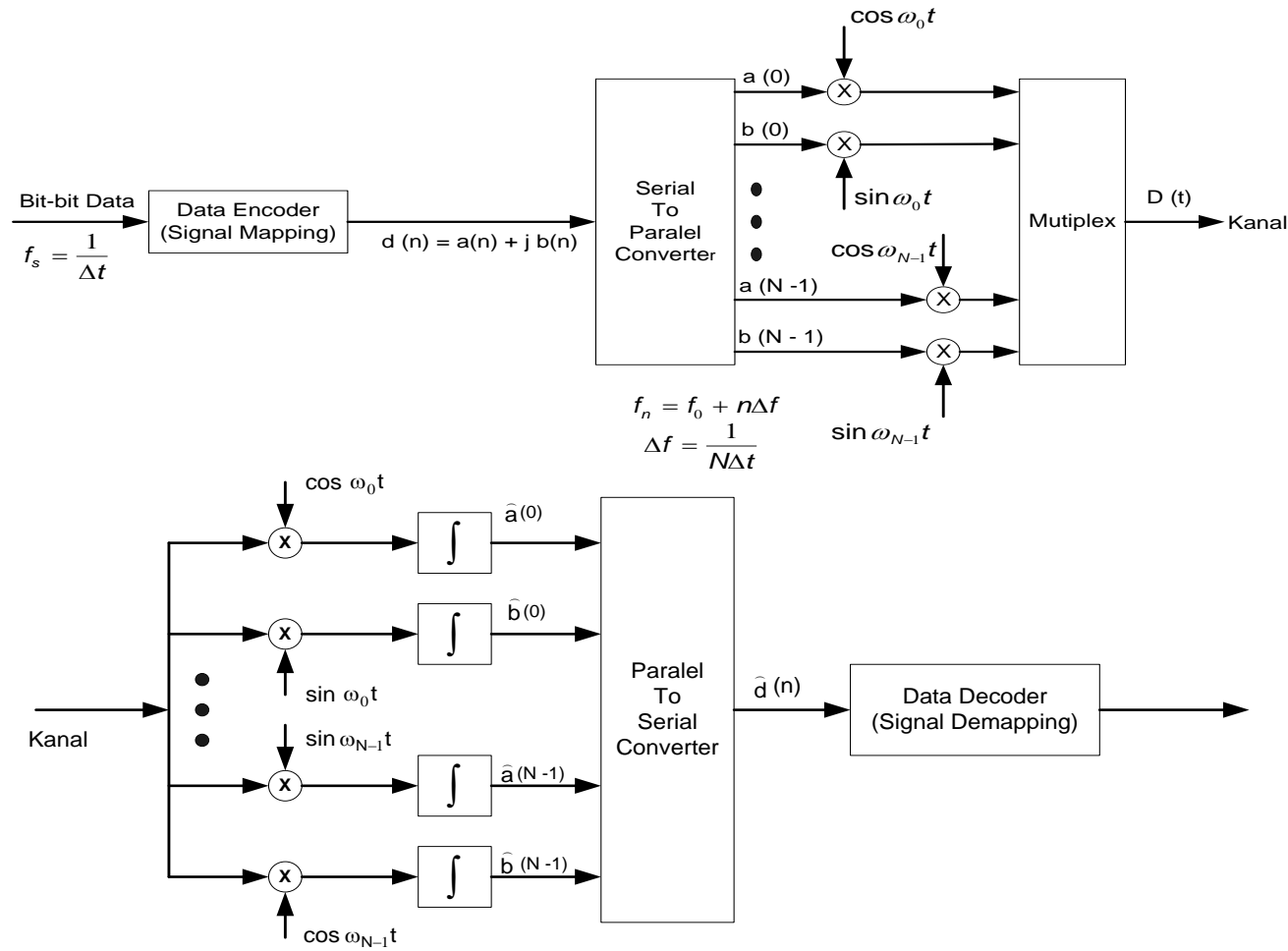

Gambar 1. Model Analog Sistem OFDM [1]

delay spread kanal transmisi. Model dasar pemrosesan secara analog dalam suatu sistem OFDM diperlihatkan pada Gambar 1.

Suatu simbol OFDM passband dapat dinyatakan sebagai berikut [9]:

$$
s(t)=\left\{\begin{array}{l}
\sum_{i=-\frac{N_{S}}{2}}^{\frac{N_{S}}{2}-1} d_{i+\frac{N_{S}}{2}} \exp \left[j 2 \pi\left(f_{C}-\frac{i+0.5}{T}\right) t\right] \\
\text { untuk } t_{S} \leq t \leq t_{S}+T \\
0, \quad t<t_{S} \wedge t>t_{S}+T
\end{array}\right.
$$

Sedangkan persamaan baseband komplek dinyatakan sebagai [9]:

$$
s(t)=\left\{\begin{array}{l}
\left.\sum_{i=-\frac{N_{S}}{2}}^{\frac{N_{s}}{2}-1} d_{i+\frac{N_{S}}{2}} \exp \left[j 2 \pi \frac{i}{T}\right) t\right] \\
\text { untuk } t_{S} \leq t \leq t_{S}+T \\
0, \quad t<t_{S} \wedge t>t_{S}+T
\end{array}\right.
$$

Guard interval antar-simbol dibutuhkan untuk menghilangkan ISI secara penuh. Diambil dari copy sinyal periode akhir simbol OFDM dan ditempatkan di depan simbol. Besar nilai guard interval terhadap periode simbol OFDM bergantung pada kebutuhan, biasanya bernilai $25 \%$ dari periode simbol OFDM, asalkan nilai tersebut harus lebih lebar dari delay spread kanal. Prinsip pembangkitan guard interval diperlihatkan pada Gambar 2.

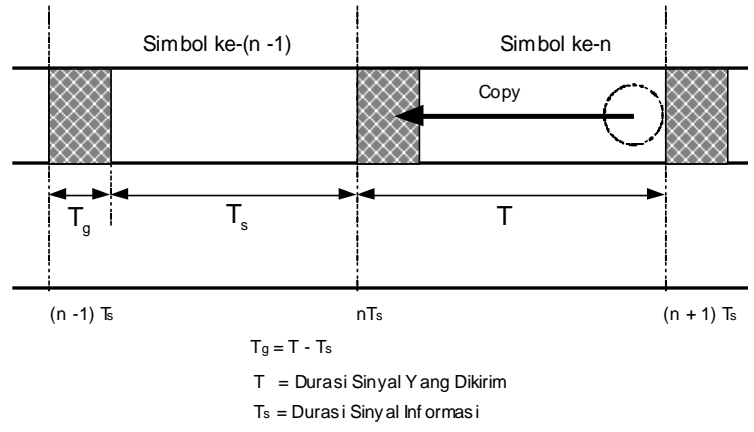

Gambar 2. Prinsip Pembangkitan Guard Interval

Dengan penambahan FEC (Forward Error Correcting) pada sistem OFDM, efek kesalahan akibat terjadinya fading tak rata antar-subcarrier dapat diminimumkan, sehingga kemudian disebut COFDM. Pada penelitian ini akan digunakan FEC dengan teknik pengkodean konvolusional dan interleaving yang telah banyak dipakai pada standar OFDM seperti Wireless LAN 802.11a dan Direct Video Broadcasting.

Operasi matematis encoding pada kode konvolusional dapat dinyatakan sebagai [4]:

$$
\mathbf{v}=\mathbf{u}^{*} \mathbf{G}
$$

dengan $\mathbf{v}$ deretan bit keluaran encoder, $\mathbf{u}$ deretan bit masukan encoder, dan $\mathbf{G}$ menyatakan respon impuls encoder. Teknik decoding yang digunakan adalah decoding Viterbi yang berdasarkan prinsip maximum likelihood. Ada dua macam cara pengambilan keputusan dalam implementasi maximum likelihood yaitu hard decision dan soft decision. Pada 


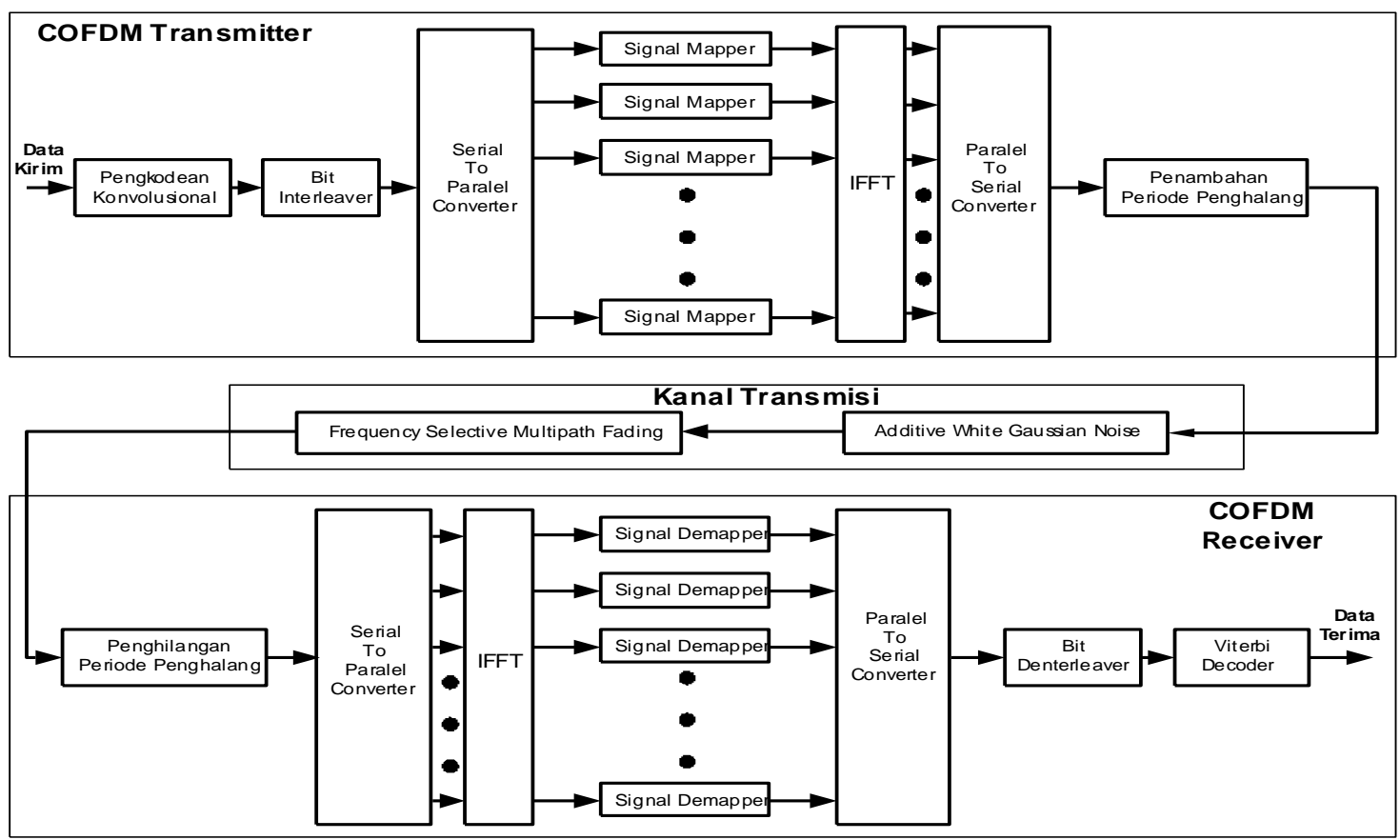

Gambar 3. Model Sistem COFDM Ekivalen Lowpass

penelitian ini digunakan metode decoding Viterbi hard decision.

Kinerja pengkodean konvolusional dibatasi oleh coding gain yang dinyatakan sebagai [8]:

$$
\text { Coding gain } \leq 10 \log \left(r d_{f}\right)
$$

dengan $r$ menyatakan laju kode dan $d_{f}$ menyatakan free distance kode konvolusional. Nilai coding gain tersebut juga terkait dengan terbatasnya kemampuan pengkodean dalam mengoreksi kesalahan (error correcting capability).

Interleaver diperlukan untuk menyebarkan pola kesalahan bit berurutan (bursty) yang diakibatkan oleh kanal fading, sehingga keterbatasan kemampuan koreksi kesalahan oleh pengkodean konvelusional dapat diatasi. Algoritma interleaving adalah menempatkan bit-bit pada kolom-kolom dan dibaca per baris, sedangkan deinterleaving melakukan hal sebaliknya. Semakin besar ukuran matriks interleaving, semakin besar pula penyebaran kesalahan dapat dilakukan, namun juga akan diperlukan peningkatan ukuran memory dan volume proses, sehingga latency-nya meningkat pula.

\section{Model Simulasi}

Untuk memudahkan implementasi, pada proses pembangkitan sinyal di pengirim COFDM dapat digunakan IFFT (Invers Fast Fourier Transform), sedangkan pada proses ekstraksi sinyal di penerima COFDM digunakan FFT (Fast Fourier Transform). Model simulasi sistem COFDM ekivalen lowpass yang dipergunakan dalam penelitian ini dijelaskan pada Gambar 3.

Struktur encoder konvolusional yang digunakan untuk FEC pada model tersebut adalah berdasarkan polinomial oktal standar [133 171] dengan constraint length 7 dan laju kode 1/2 sebagimana diperlihatkan pada Gambar 4. Selain itu, digunakan 2 macam bit interleaver, yaitu yang digunakan pada standar IS-95 dengan matriks $32 \times 18$ dan matriks optimasi $100 \times 96$.

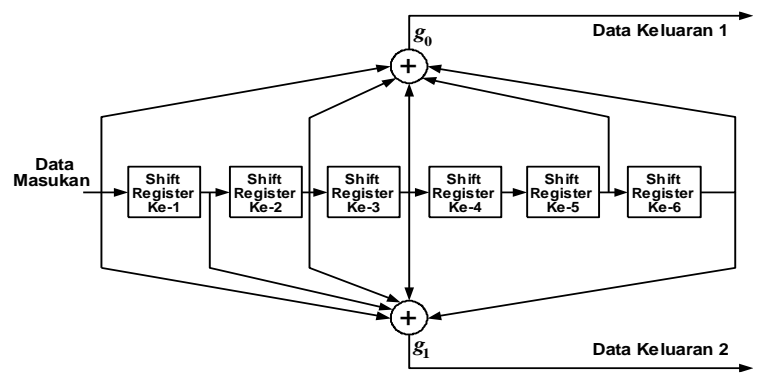

Gambar 4. Struktur Encoder Konvolusi [133 171]

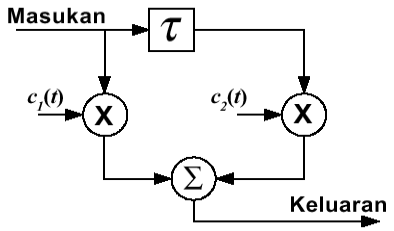

Gambar 5. Model 2-ray Rayleigh Fading

Model kanal multipath Rayleigh fading menggunakan model 2-ray Rayleigh fading, yaitu model tapped delay line dengan 2 tap. Pembangkitan koefisien tap diambil dari fungsi scattering yang dinyatakan sebagai [2]:

$$
h(\tau, t)=\lim _{N \rightarrow \infty} \frac{1}{\sqrt{N}} \sum_{n=1}^{N} \exp \left(j\left(\theta_{n}+2 \pi f_{D_{n}}\right)\right) \cdot \delta\left(\tau-\tau_{n}\right)
$$


Tabel 1. Parameter Simulasi Sistem COFDM Pada Kanal Multipath Rayleigh Fading

\begin{tabular}{|c|c|c|c|}
\hline \multicolumn{4}{|c|}{ Parameter-Parameter Dasar } \\
\hline \multicolumn{2}{|l|}{ Laju data } & \multicolumn{2}{|l|}{$400 \mathrm{kbps}$} \\
\hline \multicolumn{2}{|l|}{ Durasi simbol OFDM } & \multicolumn{2}{|l|}{$120 \mu \mathrm{s}$} \\
\hline \multicolumn{2}{|c|}{ Durasi efektif simbol OFDM } & \multicolumn{2}{|l|}{$100 \mu s$} \\
\hline \multicolumn{2}{|c|}{ Jumlah bit persimbol OFDM } & \multicolumn{2}{|l|}{48 bit } \\
\hline \multicolumn{2}{|l|}{ Durasi Guard interval } & \multicolumn{2}{|l|}{20 us } \\
\hline \multicolumn{2}{|l|}{ Frekuensi kerja } & \multicolumn{2}{|l|}{$2 \mathrm{GHz}$} \\
\hline \multicolumn{2}{|l|}{ Modulasi } & \multicolumn{2}{|l|}{ QPSK } \\
\hline \multicolumn{2}{|c|}{ Dengan Pengkodean } & \multicolumn{2}{|c|}{ Tanpa Pengkodean } \\
\hline Jumlah carrier & 48 & Jumlah carrier & 24 \\
\hline Jumlah point FFT & 64 & Jumlah point FFT & 32 \\
\hline Subcarrier spacing & $10 \mathrm{kHz}$ & Subcarrier spacing & $10 \mathrm{kHz}$ \\
\hline Bandwidth & $480 \mathrm{kHz}$ & Bandiwidth & $240 \mathrm{kHz}$ \\
\hline Sampling interval & $1,5625 \mu \mathrm{s}$ & Sampling interval & $3,125 \mu \mathrm{s}$ \\
\hline \multicolumn{4}{|c|}{ Parameter Pengkodean } \\
\hline \multicolumn{2}{|l|}{ Laju kode } & \multicolumn{2}{|l|}{$1 / 2$} \\
\hline \multicolumn{2}{|l|}{ Struktur Encoder } & \multicolumn{2}{|l|}{ [133 171] } \\
\hline \multicolumn{2}{|l|}{ Decoder } & \multicolumn{2}{|l|}{ Hard Decision Viterbi } \\
\hline \multicolumn{4}{|c|}{ Parameter Interleaver } \\
\hline $\begin{array}{l}\text { Matriks IS - } 95 \\
\text { Matriks optimasi }\end{array}$ & & \multicolumn{2}{|l|}{$\begin{array}{l}32 \times 18 \\
100 \times 96 \\
\end{array}$} \\
\hline \multicolumn{4}{|c|}{ Parameter Kanal } \\
\hline \multicolumn{2}{|l|}{ Delay Spread } & \multicolumn{2}{|l|}{$12,5 \mu \mathrm{s}$} \\
\hline \multicolumn{2}{|l|}{ Frekuensi Doppler } & \multicolumn{2}{|l|}{$0,9,56,130 \mathrm{~Hz}$} \\
\hline \multicolumn{2}{|l|}{ Bandwidth Koheren } & \multicolumn{2}{|l|}{$80 \mathrm{kHz}$} \\
\hline \multicolumn{2}{|l|}{ Karakteristik Kanal } & \multicolumn{2}{|c|}{$\begin{array}{l}\text { frekuensi selektif time-variant } \\
\text { serta slow fading dengan } \\
\text { distribusi Rayleigh }\end{array}$} \\
\hline
\end{tabular}

Simulasi sistem COFDM pada kanal AWGN dilakukan pada parameter-parameter kondisi berikut: 1) Jumlah sub-carrier: 16, 32, 64, 128, 256, 512 dan 1024.

2) Kode konvolusional menggunakan dengan polinomial oktal [133 171] laju pengkodean 1/2.

3) Matriks interleaver: $32 \times 18$ (standar IS-95). Adapun untuk kanal multipath Rayleigh fading, simulasi sistem COFDM dilakukan pada parameterparameter kondisi yang dirincikan dalam Tabel 1.

\section{Hasil Simulasi dan Analisa}

Pada kanal AWGN, sistem OFDM tanpa pengkodean memiliki kecenderungan kinerja yang sama untuk keseluruhan jumlah subcarrier. Perbedaan kinerja hanya dipengaruhi oleh perbedaan skema modulasi subcarrier QPSK dan 16-QAM yang dipergunakan, sebagaimana diperlihatkan oleh Gambar 6. Sedangkan penggunaan pengkodean dalam sistem OFDM pada kanal AWGN, untuk setiap jumlah subcarrier pada masing-masing skema modulasi subcarrier, memberikan nilai-nilai coding gain maksimum seperti terlihat di Tabel 2. Pada kanal multipath Rayleigh fading dengan perubahan frekuensi doppler 0, 9, 56 dan $130 \mathrm{~Hz}$, kinerja sistem OFDM dengan modulasi QPSK dari hasil simulasi dengan pengkodean dan tanpa pengkodean dapat diperlihatkan pada Gambar 7 . Semakin tinggi frekuensi doppler, kinerja sistem
OFDM menurun karena menguatnya fading dan pergeseran frekuensi yang berakibat pada terjadinya ICI (inter carrier interference).

Table 2. Coding gain untuk keseluruhan jumlah subcarrier pada kanal AWGN

\begin{tabular}{|c|c|c|c|c|c|c|c|}
\hline \multirow{2}{*}{$\begin{array}{c}\text { Jenis } \\
\text { Modulasi }\end{array}$} & \multicolumn{7}{|c|}{ Coding gain maksimum (dB) } \\
\cline { 2 - 8 } & $\mathbf{1 6}$ & $\mathbf{3 2}$ & $\mathbf{6 4}$ & $\mathbf{1 2 8}$ & $\mathbf{2 5 6}$ & $\mathbf{5 1 2}$ & $\mathbf{1 0 2 4}$ \\
\hline QPSK & 5 & 6 & 5 & 5 & 5 & 5 & 6 \\
\hline 16 QAM & 7 & 6 & 5 & 5 & 6 & 7 & 6 \\
\hline
\end{tabular}

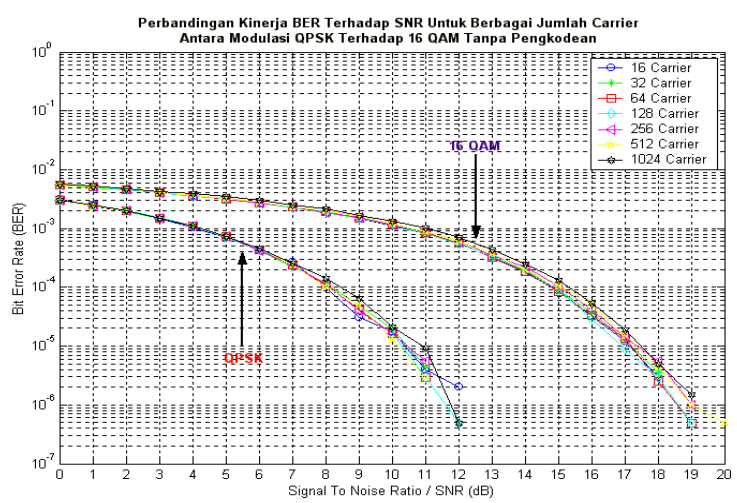

Gambar 6. Kinerja Sistem OFDM di Kanal AWGN

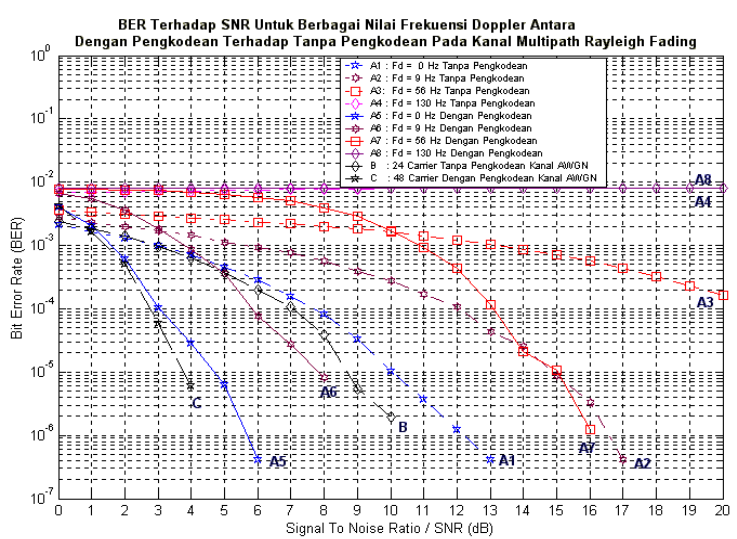

Gambar 7. Kinerja Sistem OFDM

dengan Pengkodean dan Tanpa Pengkodean pada Kanal Multipath Rayleigh Fading

Gambar 8 memperlihatkan kinerja sistem OFDM untuk jumlah subcarrier 32 dengan modulasi QPSK pada kanal multipath Rayleigh fading dengan perubahan frekuensi doppler $56 \mathrm{~Hz}$. Perbaikan kinerja oleh interleaving $32 \times 18$ kurang signifikan, yakni diperoleh perbaikan daya kurang dari $1 \mathrm{~dB}$. Hal ini disebabkan oleh terlalu kecilnya ukuran matriks, sehingga tidak memiliki kedalaman yang cukup untuk mendistribusikan pola kesalahan berurutan (bursty) oleh kanal fading. Kurang efektifnya ukuran matriks interleaving $32 \times 18$ ternyata tidak cukup terkompensasi oleh perbaikan kinerja dari pengkodean konvolusi [133 171] yang hanya memiliki constraint length 7 .

Kondisi terburuk terjadi pada kanal multipath fading dengan frekuensi doppler $130 \mathrm{~Hz}$, jika 
digunakan pengkodean dan interleaver matriks $32 \times 18$ yang tidak mampu lagi mengatasi degradasi kinerja sistem COFDM karena dominasi error burst akibat kanal fading. Kode konvolusional [133 171] yang hanya memiliki constraint length 7 tidak lagi dapat mengompensasi terlalu kecilnya ukuran matriks interleaving. Pada Gambar 9 diperlihatkan penggunaan matriks interleaver $100 \times 96$ pada kanal multipath dengan frekuensi doppler $130 \mathrm{~Hz}$ telah mampu meningkatkan kinerja sistem secara siginifikan. Nilai BER di sekitar $10^{-6}$ dicapai pada SNR 16 dB. Artinya, matriks interleaver $100 \times 96$ memiliki kedalaman memadai untuk mendistribusikan kesalahan berurutan (bursty) oleh kanal fading.

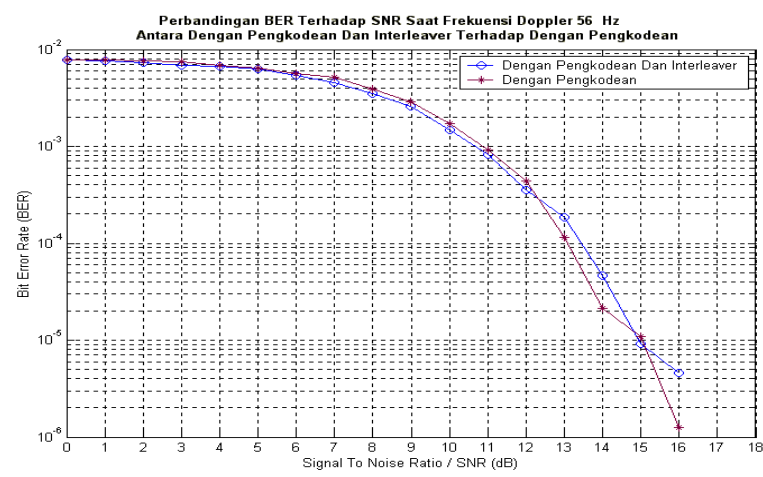

Gambar 8. Kinerja Sistem OFDM-QPSK dengan Interleaving 32×18 dan Subcarrier 32 pada Kanal Multipath Rayleigh Fading

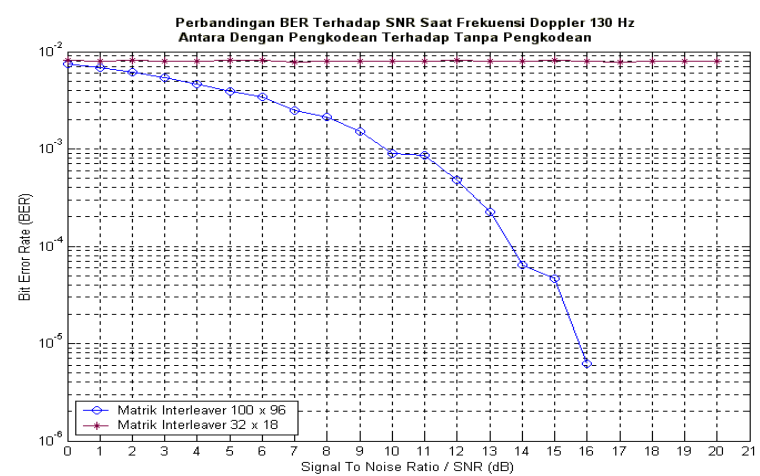

Gambar 9. Perbandingan Kinerja Sistem OFDM dengan Interleaving $100 \times 96$ dan $32 \times 18$ pada Kanal Multipath Rayleigh Fading

\section{Kesimpulan dan Saran}

Dari penelitian yang telah dilakukan dapat disimpulkan perubahan jumlah subcarrier tidak mempengaruhi kinerja OFDM pada kanal AWGN untuk masing-masing penggunaan modulasi QPSK dan 16-QAM. Coding gain maksimal pada kanal AWGN untuk modulasi QSPK berkisar 5-6 dB dan untuk modulasi 16-QAM berkisar $5-7 \mathrm{~dB}$. Semakin tingginya frekuensi doppler pada kanal multipath Rayleigh fading menyebabkan kinerja sistem memburuk akibat semakin parahnya ketakrataan fading antar-subcarrrier dan pergeseran frekuensi doppler menyebabkan inter-carrier interference.
Matriks interleaving $32 \times 18$ kurang efektif dalam memperbaiki degradasi kineja sistem COFDM, karena tidak memiliki ukuran kedalaman yang cukup untuk mendistribusikan pola kesalahan berurutan (bursty) pada kanal multipath Rayleigh fading dan tidak mendapatkan kompensasi perbaikan yang memadai dari koreksi kesalahan oleh pengkodean konvolusi [133 171]. Pada kondisi fading terburuk dengan frekuensi doppler $130 \mathrm{~Hz}$, ketika pengkodean dan matriks interleaving $32 \times 18$ tidak memberikan perbaikan kinerja sistem, matriks interleaving $100 \times 96$ dapat memberikan perbaikan yang signifikan dengan BER di sekitar $10^{-6}$ yang dapat dicapai pada SNR $16 \mathrm{~dB}$.

Hal-hal yang dapat diteliti lebih lanjut, antara lain analisis penggunaan decoder Viterbi soft decision dan carrier interleaving. COFDM juga dapat dikembangkan untuk model MC-CDMA berbasis OFDM. Teknik pembentukan sinyal ortogonalnya dapat dikembangkan dari trasformasi wavelet yang fungsi basisnya juga ortogonal.

\section{Daftar Pustaka:}

[1] Bello, P. A., Characterization of Randomly Time-Variant Linear Channel, IEEE Trans., On Communication System, Vol. CS-11, pp. 360393, Desember 1963.

[2] Cimini, L. J. Jr., Analysis and Simulation of a Digital Mobile Channel Using Orthogonal Frequency Division Multiplexing, IEEE Trans., On Comm, Vol. 33, pp. 665-675, July 1985.

[3] Hoeher, P., A. Steingar, Modelling and Emulation of Multipath Fading Channels Using 'Controlled Randomness', Institute for Communications Technology. German.

[4] Kim, Y. H., L. Song, H. G. Kim, T. Chang, H. M. Kim., Perfomance Analysis of Coded OFDM System in Time-Varying Multipath Rayleigh Fading Channels, IEEE Trans., On Vehicular Technology, Vol 48, pp. 1610-1615, September 1999.

[5] Lin, S., D. J. Costello Jr., 1983, Error Correcting Codes, New Jersey: Prentice-Hall.

[6] Nee, V. R., R. Prasad, 2000, OFDM for Wireless Multimedia Communications, Boston: Artech House.

[7] Oppenheim, A., V. Schafer, W. Ronald, 1989, Discrete-Time Signal Processing, New Jersey: Prentice Hall.

[8] Proakis, J. G., 1995, Digital Communications. New York: McGraw-Hill.

[9] Soliman, S. S., M. D. Srinath, 1990, Continuous and Discrete Signals and Systems, New Jersey: Prentice-Hall.

[10] William, Y. Z., Y. Wu, COFDM: an Overview. IEEE Transactions On Broadcasting, Vol. 41, March 1995. 